\title{
The plasminogen activator system: involvement in central nervous system inflammation and a potential site for therapeutic intervention
}

\author{
Devorah Gur-Wahnon ${ }^{1 \dagger}$, Tehila Mizrachi ${ }^{1 \dagger}$, Florence-Yehudith Maaravi-Pinto ${ }^{1}$, Athanasis Lourbopoulos ${ }^{2}$, \\ Nikolaos Grigoriadis ${ }^{2}$ Abd -Al Roof Higazi ${ }^{3}$ and Talma Brenner ${ }^{1 *}$
}

\begin{abstract}
Background: Extracellular proteases such as plasminogen activators (PAs) and matrix metalloproteinases modulate cell-cell and cell-matrix interactions. Components of the PA/plasmin system have been shown to be increased in areas of inflammation, and have been suggested to play a role in inflammatory neurologic disorders such as epilepsy, stroke, brain trauma, Alzheimer's' disease and multiple sclerosis (MS). In the present study, we evaluated the involvement of the PA system in the animal model of MS, experimental autoimmune encephalomyelitis (EAE).

Methods: EAE was induced by myelin oligodendrocyte glycoprotein (MOG) in mice deficient for the urokinase PA $\left(\mathrm{UPA}^{-1-}\right)$, or the urokinase PA receptor $\left(\mathrm{UPAR}^{-/-}\right)$. Mice were evaluated for EAE clinical signs and histopathologic parameters, and compared with wild-type (WT) EAE mice. Lymphocytes from the knockout (KO) and WT mice were analyzed for ex vivo restimulation, cytokine secretion, and antigen presentation. Finally, WT EAE mice were treated with PAI-1dp, an 18 amino acid peptide derived from the PA inhibitor protein (PAl-1).
\end{abstract}

Results: EAE was aggravated in $\mathrm{UPA}^{-/-}$and $\mathrm{UPAR}^{-/-}$mice, and this was accompanied by more severe histopathologic features and microglial activation. By contrast, specific T-cell reactivity towards the encephalitogenic antigen MOG was markedly reduced in the KO animals, as shown by a marked reduction in proliferation and pro-inflammatory cytokine secretion in these mice. Antigen presentation was also reduced in all the $\mathrm{KO}$ animals, raising an immunologic paradox. When the mice were treated with PAl-1, a peptide derived from the PA system, a marked and significant improvement in EAE was seen. The clinical improvement was linked to reduced T-cell reactivity, further emphasizing the importance of the PA system in immunomodulation during neuroinflammation.

Conclusions: Cumulatively, our results suggest a role for UPA and UPAR in EAE pathogenesis, as exacerbation of disease was seen in their absence. Furthermore, the successful amelioration of EAE by PAI-1 treatment suggests that the PA system can be considered a potential site for therapeutic intervention in the treatment of neuroimmune diseases.

\section{Introduction}

Extracellular proteolysis represents a potent and irreversible mechanism of extracellular matrix remodeling [1]. It is involved in physiologic processes and in several pathologic conditions such as tumor invasion, inflammation, tissue repair, and excitoxicity [2,3]. Cumulative data have

\footnotetext{
* Correspondence: brenner@cc.huji.ac.il

${ }^{\dagger}$ Equal contributors

'Department of Neurology, Hadassah Medical Center, P.O. Box 12000, Jerusalem 91120, Israel

Full list of author information is available at the end of the article
}

suggested that extracellular proteolysis plays a crucial role in the pathophysiology of neuronal cell death. Deleterious effects include disruption of the blood-brain barrier (BBB), amplification of inflammatory infiltrates, demyelination, and possibly disruption of cell-cell and cell-matrix interactions, which may trigger cell death. The positive effects of extracellular proteolysis include mediation of parenchymal and angiogenic recovery after brain injury [4].

The major extracellular proteolytic enzymes are the plasminogen activator (PA)/plasmin system and the matrix metalloproteinases (MMPs). PAs, specifically 
tissue PA (tPA) and urokinase-type PA (uPA), are serine proteases that cleave the zymogen plasminogen to generate the proteolytic enzyme plasmin. The PA/plasmin system has been implicated in fibrin removal, and in tissue remodeling and cell migration that occur during physiologic and pathologic processes [5], neurotoxicity, neuroprotection, and cerebral blood flow [5].

Studies on peripheral nerve injury have shown that fibrin deposition is a factor impeding axonal regeneration, whereas fibrin removal is associated with restoration of axonal function [6,7]. By contrast, activation of extracellular proteolysis is considered a pathogenic factor in demyelinating disorders such as multiple sclerosis (MS) and its animal model, experimental autoimmune encephalomyelitis (EAE). MS, an immune-mediated disease of the central nervous system (CNS), is characterized by chronic inflammatory processes. It involves the activation of CNSimmunocompetent cells and microglia, and extravasation of $\mathrm{T}$ cells and macrophages [8].

There is an ample body of literature regarding the involvement of PAs in neurologic disorders. Specifically, PA activity in MS is considered to play a major role in disturbance of the $\mathrm{BBB}$ and subsequent leukocyte migration, leading to inflammation, and causing myelin breakdown [9]. One of the earliest detectable signs of inflammatory demyelination is upregulation of urokinase type PA receptor (UPAR) and PA inhibitor (PAI-1). In the demyelinating MS lesion, TPA and UPA, forming a complex with PAI-1, are prominent in foamy macrophages, and are also a component of the MMP cascade. Significant parallel increases in components of the uPA system have been seen in MS tissue, with immunolocalization to macrophages in the active lesion, and mononuclear cells in the perivascular cuff $[4,10]$. Microglial cells isolated from the white matter of post-mortem MS tissue also have detectable UPAR $[4,11]$. Co-localization of uPAR with integrins on macrophages in the lesion further promotes adhesion to vitronectin, which in turn, leads to focal increases of PA activity [10]. During clinical EAE, the PA system was shown to be upregulated in the CNS as well [12]. Induction of tPA expression and of the PAI-1 transcript was detected in activated astrocytes in white matter. Inflammatory cells expressing uPAR also showed increased tPA and UPA activities in areas of inflammatory damage [12].

Activity of the PA system components is monitored closely and regulated by serine proteinase inhibitors, of which PAI-1 is most prominent. PAI-1 binds to active uPA and forms an uPA-PAI-1 complex, which is followed by the internalization and intracellular degradation of the complex [13].

In this study, we investigated the role of uPA and uPAR in EAE induced by myelin oligodendrocyte glycoprotein (MOG), by using uPA and uPAR knockout (KO) mice and comparing them with their wild-type (WT) counterparts. We found that the PA system affected the severity of EAE, with $\mathrm{uPA}^{-/-}$and $\mathrm{uPAR}^{-/-}$mice developing a more severe clinical course. The extent of inflammation, axonal loss, and axonal injury correlated with the more severe clinical outcome. Furthermore, pretreating EAE mice with a PAI-1-derived peptide, (PAI-1dp) [14] suppressed the development of EAE. Thus, our results support the importance of the PA components during neuroinflammation, and reveal potential sites for therapeutic intervention.

\section{Materials and methods \\ Mice}

C57BL/6 mice were purchased from Harlan Laboratories Ltd, Ein Kerem Breeding Farm, Jerusalem, Israel, and housed under specific pathogen-free conditions in the animal facility of the Hebrew University Medical School, Jerusalem, Israel, in accordance with National Institutes of Health (NIH) guidelines for the care and use of laboratory animals. KO mice deficient for uPA and UPAR against a C57BL/6 background were purchased (Jackson Immunoresearch Laboratories, West Grove, PA, USA), bred in the animal facility of the Hebrew University Medical School, and housed under specific pathogenfree conditions.

\section{EAE induction and clinical evaluation}

EAE was induced in 8-week-old female C57BL/6 mice by subcutaneous injection into the left paralumbar region of $125 \mu \mathrm{g}$ MOG $35-55$ peptide (synthesized by Sigma Laboratories, Israel) that had been emulsified in complete Freund's adjuvant (CFA) containing $5 \mathrm{mg} / \mathrm{ml}$ heat-killed Mycobacterium tuberculosis. Immediately after this injection and, again $48 \mathrm{~h}$ later, the mice were inoculated intraperitoneally with $0.5 \mathrm{ml}$ pertussis toxin (200 ng). An additional injection of $\mathrm{MOG}_{35-55}$ peptide in CFA was delivered 7 days later into the right paralumbar region.

All the animals were examined daily and evaluated for clinical signs of disease. The clinical status of the mice was graded as follows: 0 , without clinical disease; 1 , tail weakness; 2, hind limb weakness sufficient to impair righting; 3, single-limb plegia; 4, paraplegia with forelimb weakness; 5 , quadriplegia; 6 , death. According to the ethical requirements, mice that reached stage 4 were euthanaized.

\section{PAI-1-dp pre-treatment}

An 18 amino acid peptide, Ac-RMAPEEIIMDRPFLYVVRamide [14], derived from the PAI-1 protein (PAI-1-dp), was used for pre-treatment of mice induced with $\operatorname{EAE}(n=16)$ and these were compared with control placebo-treated mice $(\mathrm{n}=16)$. PAI-1-dp $0.5 \mathrm{mg} / \mathrm{kg}$ was injected 
intraperitoneal twice daily, starting 1 day preceding disease induction, and continued for 7 consecutive days. Mice were followed clinically as described above.

\section{Histopathology}

Between days 17 and 25 post-induction, animals were transcardially perfused with paraformaldehyde in $\mathrm{PBS}(\mathrm{pH}$ 7.2). The brains and spinal cords were removed, post-fixed in the same fixative, sectioned, and routinely processed for paraffin wax embedding and sectioning at $6 \mu \mathrm{m}$ (coronal brain and longitudinal spinal-cord sections). The sections were then stained with a modified Bielschowsky silver impregnation combined with hematoxylin for simultaneous evaluation of axonal injury, axonal loss and infiltration, as previously described in detail $[15,16]$.

Pathologic examination was performed under a light microscope (Axioplan-2; Zeiss), by two investigators blinded to the study groups. Photographs were captured with the aid of a digital camera (Nikon) attached to the microscope. For each animal, 10 randomly selected sections per tissue type (hemispheres, brain stem, cerebellum, and spinal cord), spaced at least $60 \mu \mathrm{m}$ apart, were examined under high-power optical fields, using a prefrontal microscope grid as previously described [15]. Sections containing both gray and white matter were stained with hematoxylin and eosin. Inflammatory foci containing at least 20 perivascular mononuclear cells were assessed in each section. The number of perivascular and parenchymal infiltrates were counted, and the data were recomputed as infiltrates $/ \mathrm{mm}^{2}$. Axonal injury (AI) was graded using the following scale 0 , normal; $1+$, a few scattered injured axons; $2+$, focal mild to moderate $\mathrm{AI} ; 3+$, scattered mild to moderate AI or focal severe AI; 4+, scattered severe AI. Axonal loss (AL) was graded as: 0 , normal; $1+$, focal mild to moderate AL; $2+$, scattered mild to moderate AL; $3+$, focal severe AL and 4+, scattered severe AL.

\section{Microglial staining}

Lectin-positive microglia/macrophages were detected in brain and spinal-cord sections using histochemical staining with biotin-labeled lectin (Sigma Aldrich, St. Louis, MO, USA) originating from Lycopersicon esculent (tomato), as previously described [15]. This molecule has been used previously for identifying microglia/ macrophages and in revealing their morphology [17]. Briefly, sections were dewaxed, dried with ethanol, and treated with proteinase $\mathrm{K}$ (Clontec Laboratories, Mountain View, CA, USA) for 2.5 minutes at $37^{\circ} \mathrm{C}$, followed by treatment with $0.3 \% \mathrm{H}_{2} \mathrm{O}_{2}$ for $15 \mathrm{~min}$ and further incubation with $0.3 \%$ Triton-X in Tris-buffered saline containing an avidin-biotin blocking agent (Vector Laboratories, Burlingame, CA, USA). The sections were then incubated with the biotin-labeled lectin $(3 \mu \mathrm{g} / \mathrm{ml})$ for 2 hours at room temperature, and streptavidin was added to permit visualization with an appropriate chromogen (NovaRed; Vector Laboratories).

The lectin-positive microglia/macrophages were readily identified and morphologically distinguishable from blood vessels, which this molecule also stains $[17,18]$. The number of lectin-positive microglia/macrophages was counted, and the data were recomputed as lectinpositive cells $/ \mathrm{mm}^{2}$.

\section{Lymphocyte proliferation assay}

Pooled lymph-node cells (LNCs) were prepared from inguinal, axillary, and mesenteric lymph nodes or spleens derived from naive mice or from mice that had been subcutaneously inoculated 9 days earlier with MOG $35-55$ peptide in CFA. The in vitro response of the lymphocytes was assayed in triplicate wells of 96-well flat-bottom microtiter plates. A total of $2 \times 10^{5} \mathrm{LNCs}$, suspended in $0.2 \mathrm{ml}$ RPMI supplemented with 5\% FCS, was added to each well with or without $100 \mu \mathrm{g} / \mathrm{ml} \mathrm{MOG}_{35-55}$ peptide. At $48 \mathrm{~h}$ after seeding, $1 \mu \mathrm{Ci}^{3}[\mathrm{H}]$ thymidine (Amersham Pharmacia Biotech, Amersham, Buckinghamshire, UK) was added to each well, and the plates were incubated for an additional $18 \mathrm{~h}$. The plates were then harvested with a semi-automated harvester onto a glass fiber filter, and the radioactivity was determined by liquid scintillation assay.

\section{Antigen presentation assay}

Antigen-presenting cells (APCs) were derived from spleens of $\mathrm{WT}, \mathrm{uPA}^{-1-}$ or $\mathrm{uPAR}^{-/-}$naive mice. Before co-culture with responder $\mathrm{T}$ cells, the splenocytes were irradiated at $3000 \mathrm{rad}$, so that the proliferation in the co-culture assays could be attributable solely to the responder $\mathrm{T}$ cells. The latter were obtained from $\mathrm{MOG}_{35-55^{-}}$ stimulated LNCs derived from MOG-immunized WT mice. The cells were maintained in MOG-containing medium for 4 days, after which the medium was replenished and supplemented with interleukin (IL)-2 $(20 \mu \mathrm{g} / \mathrm{ml})$ for an additional 5 days. For the antigen presentation assay, 50,000 responder $\mathrm{T}$ cells (per well) were co-cultured with 300,000 irradiated splenocytes derived from WT, $\mathrm{uPA}^{-/-}$or $\mathrm{uPAR}^{-/-}$naive mice, in the presence of MOG $(50 \mu \mathrm{g} / \mathrm{ml})$ for $72 \mathrm{~h}$. The cells were cultured in RPMI 1640 containing 10\% FCS supplemented with $5 \times 10^{-5} \mathrm{~mol} / \mathrm{l} 2-\mathrm{ME}, 1 \mathrm{mmol} / \mathrm{l}$ sodium pyruvate, 1/100nonessential amino acids, $2 \mathrm{mmole} / \mathrm{L}$ L-glutamine 2, and $100 \mathrm{U}$ of penicillin/ml (Austria). Responder T-cell proliferation was assessed by $\left[{ }^{3} \mathrm{H}\right]$ thymidine incorporation.

\section{Statistical analysis}

The histopathologic data were analyzed using SPSS software (version 18.0). The values of all the data are expressed as mean \pm standard error (SE). Semi-quantitative data for the two groups ( $\mathrm{AI}$ and $\mathrm{AL}$ ) were analyzed using 
the Pearson $\chi^{2}$ test or Fisher's exact test, where appropriate, and the data were displayed as bar graphs. The difference between the two groups was compared using the Mann-Whitney $U$-test or Student's $t$-test, as appropriate. The remaining data were analyzed using Student's t test and one-way ANOVA, according to Dunnett, and Fisher's exact test. $P<0.05$ was considered significant.

\section{Results}

\section{Aggravation of EAE in $\mathrm{uPA}^{-/-}$and $\mathrm{uPAR}^{-/-}$mice}

Several components of the plasminogen activation cascade have been found to be involved in CNS pathologies, including stroke, TBI, MS, and EAE. To evaluate the effect of UPA and UPAR on processes related to CNS inflammation, we examined their involvement in EAE, the experimental inflammatory and demyelinating autoimmune disease used to study human MS. EAE was induced in $\mathrm{uPA}^{-/-}$, $\mathrm{uPAR}^{-/-}$, and WT mice. All the $\mathrm{KO}$ mice tested presented more severe neurologic scores and delayed recovery compared with the WT mice (Figure 1). In the $\mathrm{uPA}^{-/-}$mice, the mean disease severity was $1.8 \pm 0.2$ compared with $1.1 \pm 0.2$ in the WT mice (a 64\% increase) (Figure 1A). $\mathrm{uPAR}^{-/-}$mice had significantly more severe disease than the WT mice in the chronic phase of the disease (Figure 1B), with mean disease severity being $2.5 \pm 0.4$ for $\mathrm{uPAR}^{-/-}$versus $1.7 \pm 0.2$ for WT (a 47\% increase over WT) (Figure 1B). Notably, whereas the WT mice showed remission of the disease about 30 days post-induction, both the $\mathrm{uPA}^{-1-}$ and the $\mathrm{uPAR}^{-/-}$animals failed to recover.

\section{Neuropathologic parameters in $\mathrm{uPA}^{-/-}$and $\mathrm{uPAR}^{-/-}$mice}

The marked difference in the clinical score of the $\mathrm{uPA}^{-/-}$ and $\mathrm{uPAR}^{-/-}$animals was consistent with the neuropathologic processes in their spinal cords during the chronic phase of the disease. Evaluation of cellular infiltration (infiltrates $/ \mathrm{mm}^{2}$ ), AI, and AL identified a massive infiltration of mononuclear cells in the spinal cords of the $\mathrm{uPA}^{-/-}$animals (Figure 2A) accompanied by a marked increase in AI and $\mathrm{AL}$ (Figure 3B and D) compared with WT EAE mice $(P<0.001, p<0.05, p<0.001$ respectively). Concomitantly, the $\mathrm{uPA}^{-/-}$group exhibited severe AI with more ovoids, spheroids, and dystrophic axons, even in areas without striking perivascular infiltration, but displayed only some parenchymal infiltrates compared with the corresponding WT controls (Figure 2a1,a2). Milder differences were noted in the brainstem, cerebelli, and hemispheres of the animals (data not shown).

Similarly, the $\mathrm{uPAR}^{-/-}$mice exhibited an increased inflammatory burden in their spinal cords (Figure 2B) $(\mathrm{p}<0.05)$ and a marked AL (Figure $3 C)(P<0.001)$, albeit with similar levels of AI (Figure $3 \mathrm{~A})$ during the chronic phase, compared with the WT EAE-induced mice. These neuropathologic data are in agreement with the clinical courses of the $\mathrm{KO}$ and WT animals, which displayed a similar acute phase and a different chronic phase.

Microglia and blood-borne macrophages play an important role in EAE pathogenesis. Evaluation of activated lectin-positive microglia/macrophages per $\mathrm{mm}^{2}$ during the chronic phase of the disease showed a twofold increase within the spinal cords of the $\mathrm{uPAR}^{-/-}$mice compared with the WT control mice (Figure 4).

\section{Immune responses to $\mathrm{MOG}_{35-55}$ and antigen presentation} in $\mathrm{uPA}^{-/-}$and $\mathrm{uPAR}^{-/-}$mice

In all the described models of EAE, the cells that initiate the disease are predominantly myelin-reactive $\mathrm{CD}_{4}^{+} \mathrm{T}$ helper cells. These antigen-specific autoimmune T cells first contact a naive intact $\mathrm{BBB}$, and are able to extravsate through the $\mathrm{BBB}$, because of their active status. In the CNS, as a result of presentation of appropriate antigens, the cells undergo further activation.

To assess the differences between the $\mathrm{KO}$ mice and the WT mice, we performed two sets of experiments:
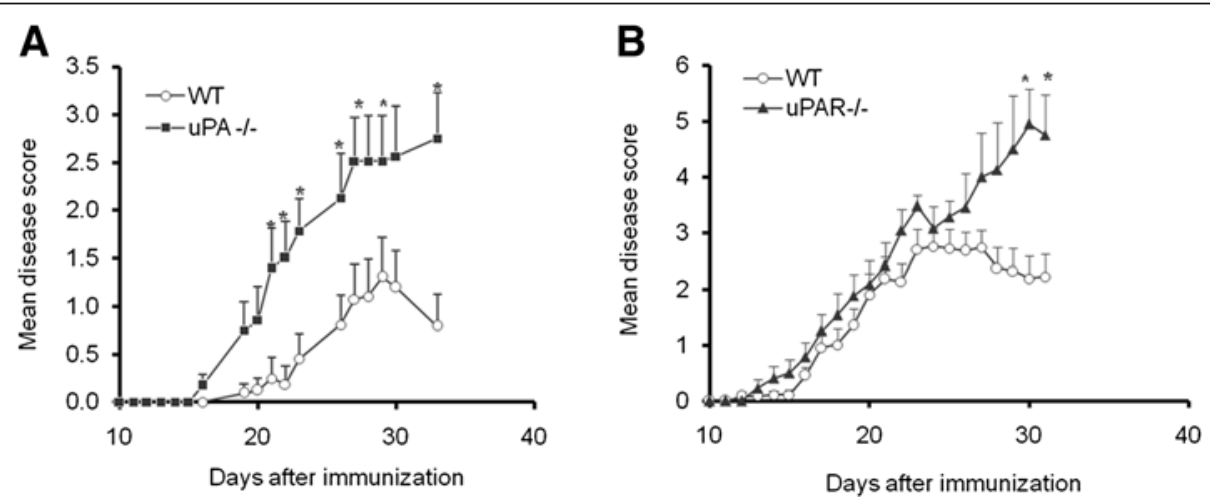

Figure 1 Experimental autoimmune encephalomyelitis (EAE) is aggravated in mice deficient for the urokinase plasminogen activator $\left(\mathbf{u P A}^{-1-}\right)$, or the urokinase plasminogen activator receptor $\left(\mathrm{UPAR}^{-1-}\right)$. (A) EAE clinical severity in $\mathrm{UPA}^{-/-}$mice and control wild-type (WT) mice. (B) EAE clinical severity in $\mathrm{UPAR}^{-1-}$ mice and control WT mice. $(\mathbf{A}, \mathbf{B})$ Results are expressed as the mean clinical score \pm standard error $(\mathrm{SE})$ of three separate experiments $\left({ }^{*} P<0.05\right)$. 

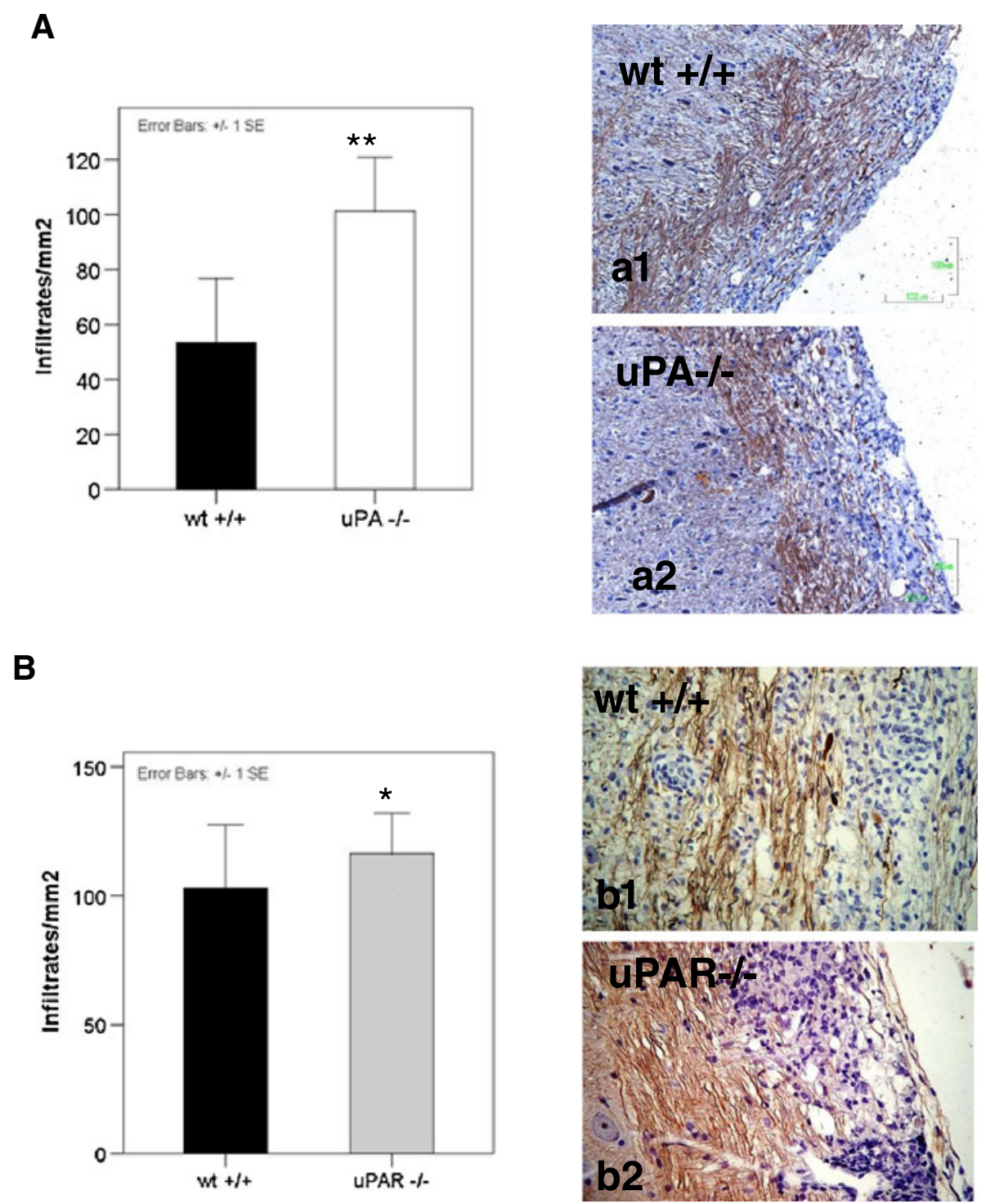

Figure 2 Neuropathology in the spinal cords of EAE in urokinase plasminogen activator ( $\mathrm{UPA}^{-1-}$ ), or the urokinase plasminogen activator receptor ( $\mathbf{u P A R}^{-l-}$ ) mice compared with WT mice. The results are presented as mean \pm standard error (SE) (infiltrates $/ \mathrm{mm}^{2}$ ). (A) uPA ${ }^{-1}$ animals exhibited an almost twofold greater inflammatory burden $\left.{ }^{* *} P<0.001\right)$. (a1,a2) Representative photographs (hematoxylin plus Bielschowsky stain) Magnification $\times 200$. (B) $\mathrm{uPAR}^{-/-}$animals exhibited significantly greater inflammation $\left({ }^{*} P<0.05\right)$. (b1,b2) Representative photographs, magnification $\times 200$.

T-cell activation, evaluated by $\mathrm{T}$-cell proliferation and pro-inflammatory cytokine secretion, and an antigenpresenting assay. Unexpectedly, and unrelated to disease severity, the T-cell reactivity towards the encephalitogenic $\mathrm{MOG}_{35-55}$ peptide of cells derived from the $\mathrm{uPA}^{-1-}$ and $\mathrm{uPAR}^{-1-}$ mice was found to have a significantly lower response to the tested antigen compared with WT cells. This presented as reduced proliferation of $\mathrm{MOG}_{35-55}$ encephalitogenic cells (Figure 5A), and reduced secretion of pro-inflammatory cytokines. Absence of uPA resulted in a $57 \%$ reduction in IFN- $\gamma$ secretion and a $62 \%$ reduction in tumor necrosis factor (TNF)- $\alpha$
(Figure 5B,C). Similarly, in the absence of uPAR, a 70\% reduction in IFN- $\gamma$ secretion and a $45 \%$ reduction in TNF- $\alpha$ secretion were seen.

We then examined the ability of APCs cultured from $\mathrm{uPA}^{-/-}$and $\mathrm{uPAR}^{-1-}$ mice to mount an immunologic reaction compared with APCs from WT animals. APCs were prepared from $\mathrm{uPA}^{-/-}$, and $\mathrm{uPAR}^{-1-}$, and WT animals (as described in Materials and Methods), and plated with anti-MOG $\mathrm{M}_{35-55}$-specific lymphocytes in the presence of $\mathrm{MOG}_{35-55}$. Figure 5D shows a reduction in lymphocyte proliferation in the presence of APCs from $\mathrm{uPA}^{-1-}$ and $\mathrm{uPAR}^{-1-}$ animals compared with that in the 


\section{Axonal Injury (AI)}
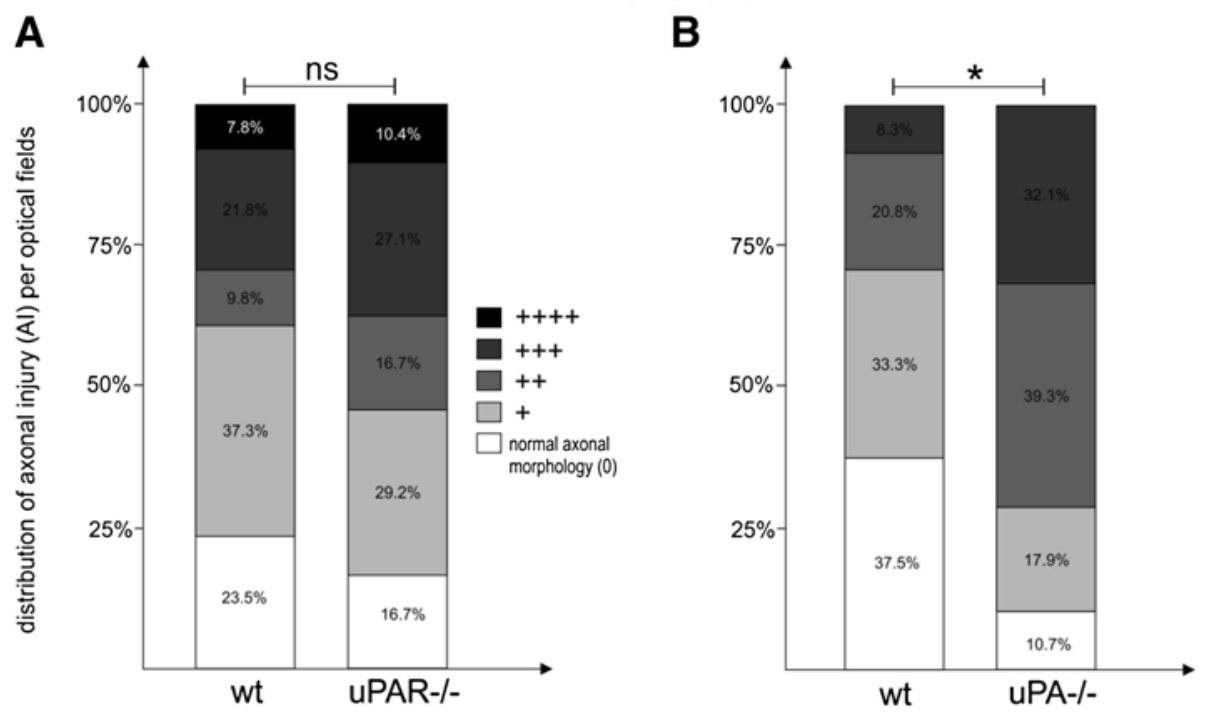

Axonal Loss $(\mathrm{AL})$
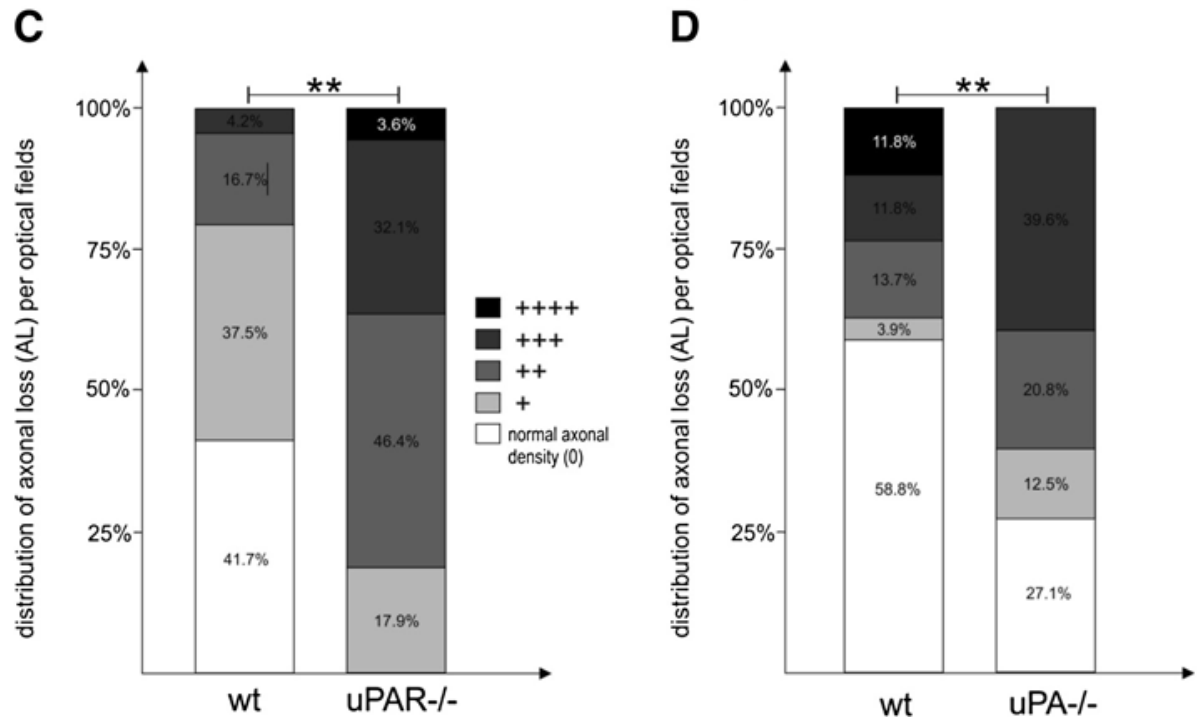

Figure 3 Axonal injury and axonal loss in experimental autoimmune encephalomyelitis (EAE) in mice deficient for the urokinase plasminogen activator (uPA ${ }^{-/-}$), or the urokinase plasminogen activator receptor (uPAR ${ }^{-/-}$) compared with EAE wild-type (WT) mice. Rsults are presented as percentage distribution of severity. $(\mathbf{A}, \mathbf{C}) \mathrm{UPAR}^{-1-}$ mice exhibited (A) similarly active axonal injury (AI) and (C) significantly greater axonal loss (AL). (B,D) $\mathrm{UPA}^{-/-}$mice exhibited (B) more severe $\mathrm{Al}$ and $(\mathbf{D})$ more $\mathrm{AL}$. ${ }^{*} P<0.05,{ }^{*} P<0.001$.

WT animals. The results indicate a reduction in antigen presentation capacity in the $\mathrm{uPA}^{-/-}$and $\mathrm{uPAR}^{-/-}$animals.

\section{Amelioration of EAE after PAI-1 administration}

Cumulatively, these results suggest that in addition to their effect on the inflammatory system, uPA and UPAR play other protective roles. Indeed, uPA and UPAR are known to initiate and stimulate the fibrinolytic system, suggesting that, in sum, the balances of their effects are neuroprotective. In an attempt to inhibit the deleterious, pro-inflammatory effects of the lack of UPA and UPAR, and to increase their profibrinolytic effect, we injected the animals with the PAI-1-derived 18 amino acid peptide (PAI-dp). This peptide correlates with the docking site of PAI-1 within the UPA protein. Binding of the peptide to uPA prevents binding of the intrinsic PAI-1 to uPA, thereby preventing the inhibitory effect of PAI-1. We previously reported that PAI-dp inhibits the binding of uPA to PAI-1 and in so doing, increases the plasminogen activation ability of uPA, and inhibits uPA-induced signal transduction [14]. 


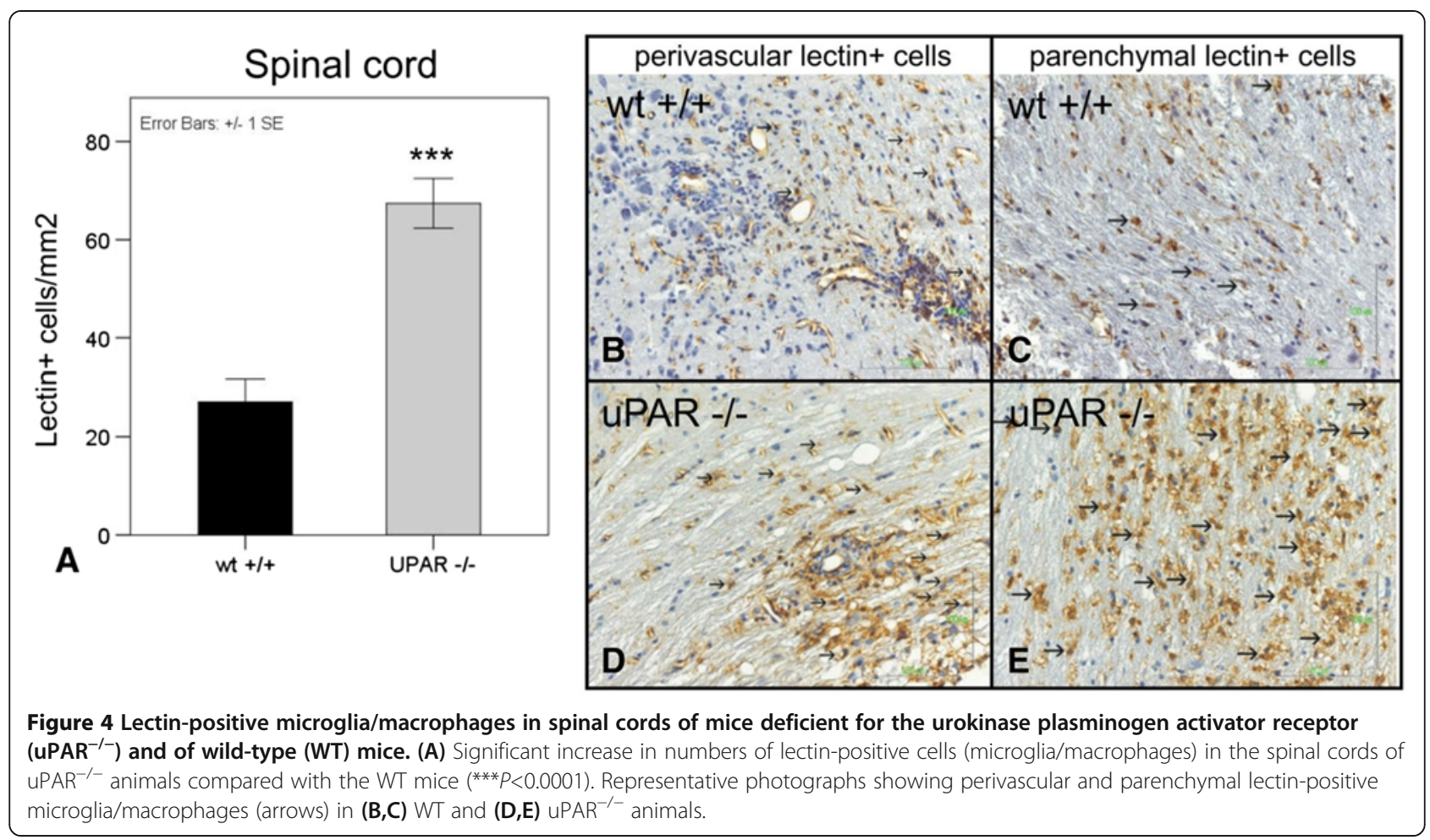

WT mice induced with EAE were injected with PAI$1 \mathrm{dp}$, and compared with placebo-injected EAE mice. As seen in Figure 6, preventative administration of PAI-dp markedly and significantly suppressed the disease, with disease severity being reduced by $83 \%$ (from $1.2 \pm 0.3$ to $0.2 \pm 0.04)$. Furthermore, T-cell reactivity towards the encephalitogenic $\mathrm{MOG}_{35-55}$ peptide was reduced in the PAI-1dp-injected mice. As shown in Figure 7, T-cell proliferation was reduced (Figure 7A) in lymphocytes derived from PAI-1-injected mice. Accordingly, the proinflammatory cytokines IFN- $\gamma$ and IL-17 were also reduced in these mice (Figure7B).

\section{Discussion}

The data presented in this study show that the PA system plays a role in CNS inflammation. Using mice lacking $\mathrm{UPA}$ and $\mathrm{uPAR}$, we found that during EAE, mice exhibit a very severe disease, with impaired recovery. The neuropathologic findings were consistent with disease severity; $\mathrm{uPA}^{-/-}$and $\mathrm{uPAR}^{-/-}$mice showed an increase in $\mathrm{AL}$ and a massive infiltration of mononuclear cells into the spinal cord.

In addition, the importance of microglial activation in EAE pathology is known, and we found that microglial activation was increased twofold within the spinal cord of $\mathrm{uPAR}^{-/-}$mice. Microglia are resident APCs that make up to $10-20 \%$ of all the glial cells in the CNS [19]. In MS and EAE, microglia are activated, express high levels of major histocompatibility complex class II, and function as APCs [20,21]. The increase in lectin-positive microglia/macrophage activation seen in the $\mathrm{UPAR}^{-/-}$ animals is in accordance with the clinical severity of the disease.

Our results are in agreement with previously reported results. East et al. reported a more severe $\mathrm{EAE}$ in $\mathrm{tPA}^{-1-}$ mice, characterized by incomplete recovery and increased neurologic deficit, and also reported persisting inflammatory cuffs of mononuclear cells and a greater degree of demyelination in $\mathrm{uPAR}^{-/-}$mice [9]. Another report by East et al. showed that mice lacking the plasminogen inhibitor PAI-1 developed milder EAE without clinical relapse, and with an overall reduction in neuroinflammation [22].

These findings, together with those from the earlier part of the current study, prompted us to attempt to treat EAE using the PAI-dp, the peptide derived from the PAI-1 protein. PAI-1dp inhibits the action of PAI-1, thereby prolonging the presence and proteolytic activity of uPA. Importantly, we found that when EAE mice were pretreated with PAI-1dp, they developed a markedly less severe disease, accompanied by a reduction in T-cell reactivity. To our knowledge, this amelioration of EAE after the novel approach of injecting peptides derived from the PA system has not been reported previously.

The roles played by the PA system in the pathogenesis of EAE could be ascribed to a number of different mechanisms, such as regulation of fibrin deposition at sites of inflammation, and effects on cell trafficking into the 

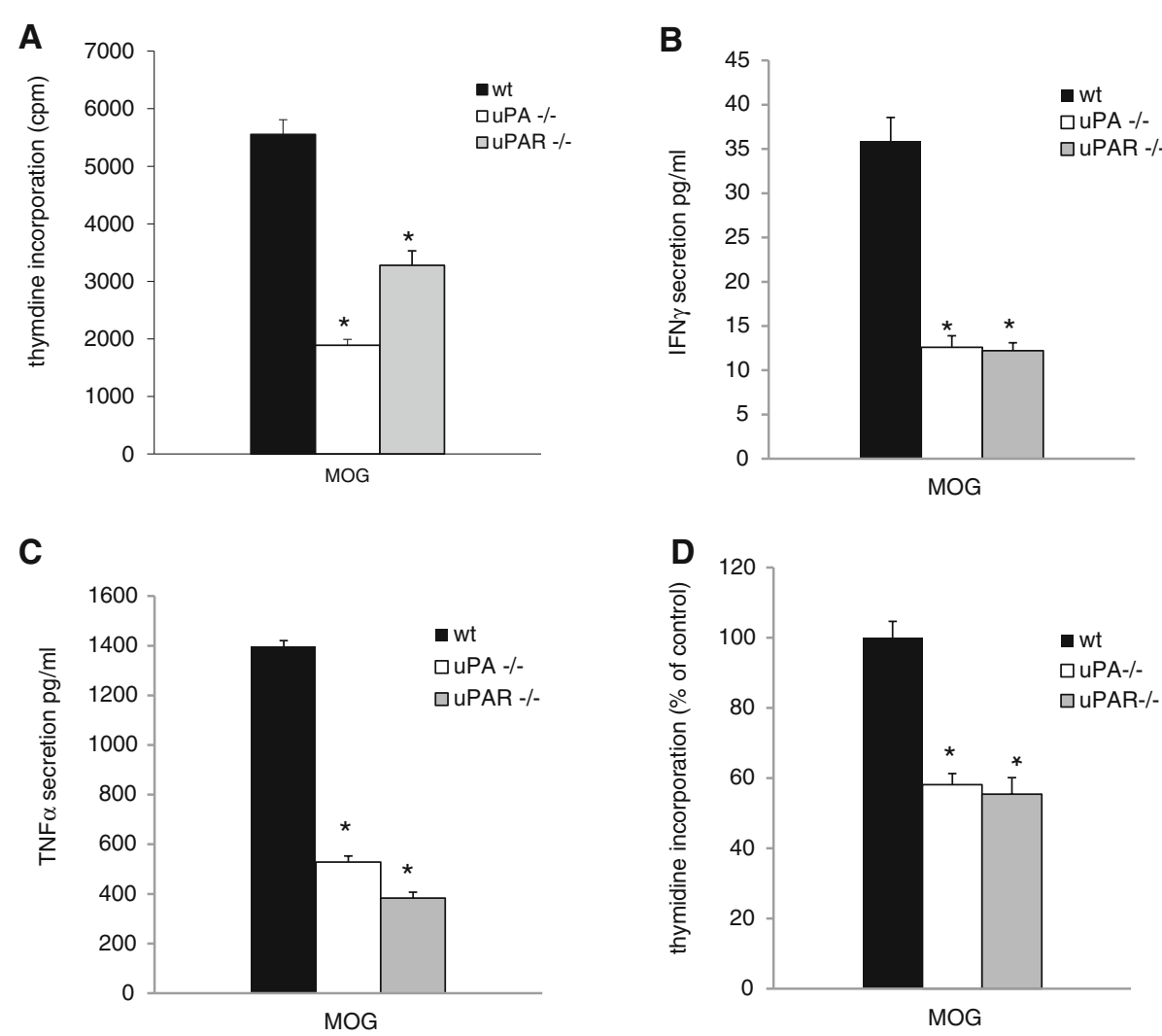

Figure 5 mice deficient for the urokinase plasminogen activator $\left(\mathrm{uPA}^{-/-}\right)$, or the urokinase plasminogen activator receptor (uPAR ${ }^{-/-}$) show reduced T-cell reactivity to myelin oligodendrocyte glycoprotein (MOG) $35-55$ and reduced antigen presentation. (A) Proliferation of lymphocyte from all the tested groups was checked by $\left[{ }^{3} \mathrm{H}\right]$ thymidine incorporation in the presence of $\mathrm{MOG}_{35-55}$. (B). The effect of uPA and UPAR deficiency on T helper 1 (Th1) cytokine secretion. Lymphocytes from $\mathrm{UPA}^{-/-}$, $\mathrm{UPAR}^{-/-}$and WT mice were stimulated with $\mathrm{MOG}_{35-55}$, the media were collected after 24 hours, and the secreted (B) interferon (IFN)- $\gamma$ and (C) tumor necrosis factor (TNF)-a were measured by ELISA. (A-C) Results are expressed as mean \pm standard error (SE) of three separate experiments ( $\left.{ }^{*} P<0.05\right)$ (D) Effect of uPA and uPAR deficiency on antigen presentation measured by $\mathrm{MOG}_{35-55}$ specific T-cell proliferation. Lymphocyte proliferation was checked by $\left[{ }^{3} \mathrm{H}\right]$ thymidine incorporation using APCs from knockout (KO) or WT mice in the presence of $M_{0} G_{35-55}$. Results are expressed as the mean \pm SE of four separate experiments $\left({ }^{*} P<0.05\right)$.

CNS. Fibrin, the end product of PA proteolytic activity, participates in a variety of cellular responses associated with inflammation $[23,24]$ by binding to a range of receptors that are expressed on leucocytes, macrophages, and monocytes [25]. Fibrinogen-deficient mice show delayed inflammatory responses to lipopolysaccharide [26]. Because fibrin is capable of modulating inflammation via a number of different mechanisms, it is clear that removal of fibrin by enhancing fibrinolysis can produce beneficial results.

Although the $\mathrm{uPA}^{-1-}$ and $\mathrm{uPAR}^{-1-}$ mice exhibited more severe disease, there was a reduction in their immune response compared with WT mice. This was reflected by a reduction in proliferative lymphocytes and a reduced ability to present antigen. These findings point to a paradoxical situation in which the $\mathrm{KO}$ mice present with more severe disease, a condition that is usually characterized by high lymphocyte proliferation and cytokine induction, but in this study showed just the opposite results. The PA system is considered to be both pro-inflammatory and anti-inflammatory. The former is related to the mounting of correct innate and adaptive immune responses, whereas the latter is related to prevention of extracellular fibrin deposition [13]. The PA system components involvement in two opposing processes might explain these conflicting results.

There is an intriguing link between the uPA/uPAR system and the immune system. Both uPA and uPAR expression were shown to be modulated by inflammatory mediators. TNF- $\alpha$, IFN- $\gamma$, and IL- 1 were found to increase uPA expression on macrophages [27,28]. Activated T lymphocytes express uPA and uPAR [29,30], and stimulation with phorbol esters and T-cell receptor (TCR)-mediated stimulation results in substantial upregulation of uPA and UPAR in T cells [31]. uPAR is co-expressed with CD25 (IL-2R), and its expression in TCR-mediated T-cell activation has been established [32]. Furthermore, uPAR is upregulated by exposure to 


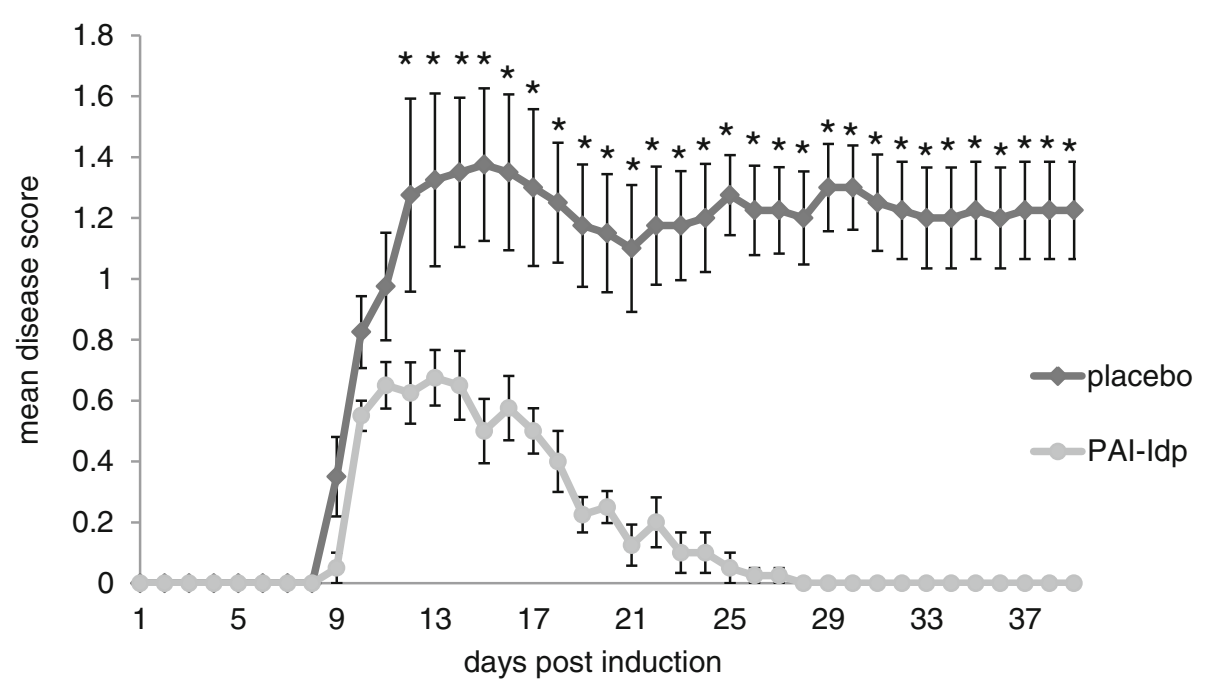

Figure 6 Administration of the plasminogen activator inhibitor-derived peptide PAI-1dp ameliorated the clinical course of experimental autoimmune encephalomyelitis (EAE). EAE was induced in wild-tupe (WT) mice by immunization with myelin oligodendrocyte glycoprotein (MOG) $35-55$. The animals were given either placebo or PAl-dp $0.5 \mathrm{mg} / \mathrm{kg}$ twice daily by intraperitoneal injection. Results are expressed as the mean clinical score \pm standard error (SE) of three separate experiments. ( $n=16$ for each group). The results are the mean of three separate experiments.

IL-2 and IL-4, but not to several other cytokines [33]. Conversely, there is substantial evidence suggesting that UPA is a modulator of immune and inflammatory responses. For example, early reports showed that PA could act as a lymphocyte mitogen [32]. Thus, bidirectional communication links the UPA/uPAR system and the inflammatory cytokine networks. Therefore, the profound effect of uPA/uPAR deficiency on lymphocyte activation in our model is not unexpected, and the severe clinical outcome can be explained by the inability of the $\mathrm{KO}$ mice to mount a protective immune response. Similar results were reported by Gyetko et al. [34] who investigated the ability of $\mathrm{uPA}^{-/-}$mice to mount a protective host defense during infection with the opportunistic yeast Cryptococcus neoformans. In the absence of uPA, the mice failed to mount an adequate immune defense against the yeast, resulting in a lethal defect in cell-mediated immune responses.

When targeting the PA system for treatment of EAE/ MS, it is important to bear in mind its major role in the fibrinolytic system, and that manipulation of the PA system might cause unwanted effects in the coagulation/fibrinolytic system. Recombinant tPA has been in clinical use for treatment of myocardial infarct. However, it can be given only once in such cases, and not as an ongoing treatment because it causes excessive bleeding, and therefore cannot be used for treatment of MS.

It is interesting that mice lacking uPA do not have major thrombotic disorders [35]. This is most probably
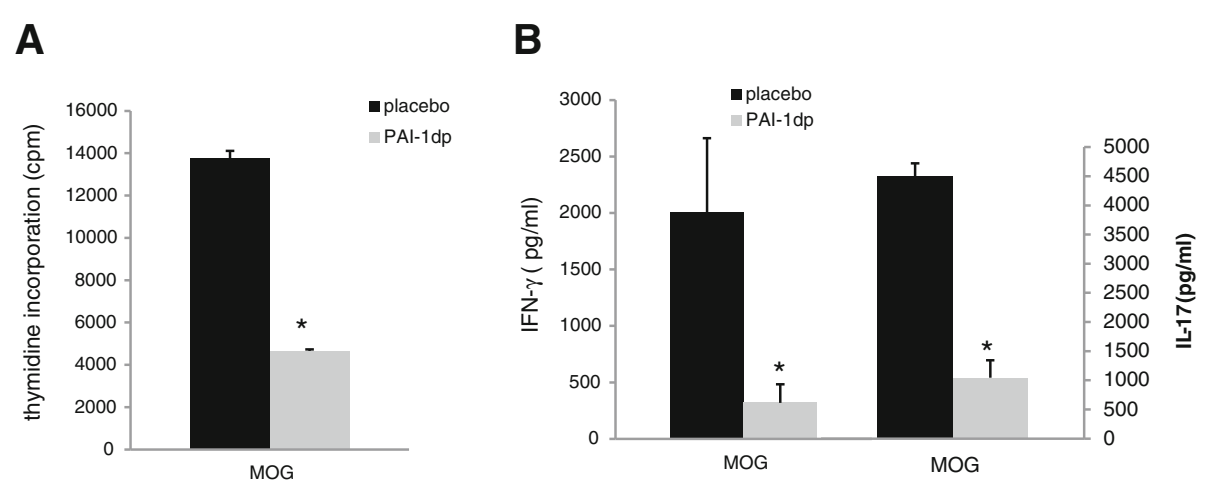

Figure 7 Administration of PAI-1dp reduces T-cell reactivity towards MOG $_{35-55}$ peptide. A. PAl-1dp pre-treatment reduced T cell proliferation induced by $\mathrm{MOG}_{35-55}$. B. Reduced secretion of the pro-inflammatory cytokines IFN- $\boldsymbol{Y}$ and IL-17. The results are the mean standard error (SE) of three separate experiments $\left({ }^{*} P<0.05\right)$. 
because of the redundant fibrinolytic function of uPA, which, at least in the vascular compartment, can be substituted for by tPA. Double uPA-tPA KO mice show extensive thrombotic disorders similar to those in plasminogen $\mathrm{KO}$ mice [36]. In addition, disruption of the PAI-I gene in mice does not appear to impair hemostasis, but is associated with increased resistance to thrombosis and with a mild hyperfibrinolytic state characterized by enhanced in vivo clot lysis [37]. Interestingly, despite the minor influence of the disruption of these genes in the naïve state, the effects of disruption become apparent upon disease induction. This suggests that the biologic consequences of PA system gene inactivation might be more significant in disease states.

\section{Conclusions}

It is probable that the PA system plays both harmful and beneficial roles in MS/EAE, and that there is a balance between injury and recovery. This balance may be regulated via the expression and secretion of cytokines and proteolytic enzymes. Our results suggest that attenuation of uPA activity by pre-treatment with PAI-1-dp may be a potential mechanism for treatment of CNS inflammatory and demyelinating diseases.

\footnotetext{
Abbreviations

APC: Antigen-presenting cell; BBB: Blood-brain barrier; CFA: complete Freund's adjuvant; CNS: Central nervous system; EAE: Experimental autoimmune encephalomyelitis; FCS: fetal calf serum; IFN: Interferon; IL: Interleukin; KO: Knockout; LNC: Iymph-node cell; MOG: Myelin oligodendrocyte glycoprotein; MMP: Matrix metalloproteinase; MS: Multiple sclerosis; NIH: National Institutes of Health; PA: Plasminogen activator; PAI1: Plasminogen activator inhibitor protein; PBS: phosphate-buffered saline; TNF: Tumor necrosis factor; tPA: Tissue plasminogen activator; uPA: urokinase plasminogen activator; uPAR: urokinase plasminogen activator receptor; WT: Wild-type.
}

\section{Competing interests}

The authors declare that they have no competing interest.

\section{Authors' contributions}

TM, FYMP and DGW performed the animal and cell culture studies. AL and NG performed the pathological studies, the tissue staining and evaluation. TB and AAH were involved in study design. TB and DGW were involved in writing the manuscript. All authors approved the final manuscript.

\section{Acknowledgements}

We thank Mrs Camille Sicsic for her skillful assistance. The study was funded by a FightMG grant from the European community, and by the Israeli Ministry of Health Chief Scientist Fund.

\section{Author details}

'Department of Neurology, Hadassah Medical Center, P.O. Box 12000, Jerusalem 91120, Israel. ${ }^{2}$ Department of Neurology, Aristotle University Hospital, 1stilpe Kyriakidi str, Thessaloniki GR 54636, Greece. ${ }^{3}$ Department of Biochemistry, Hadassah Medical Center, P.O. Box 12000, Jerusalem 91120, Israel.

Received: 10 April 2013 Accepted: 24 September 2013

Published: 11 October 2013

\section{References}

1. Werb Z: ECM and cell surface proteolysis: regulating cellular ecology. Cell 1997, 91:439-442.

2. Matrisian LM: Metalloproteinases and their inhibitors in matrix remodeling. Trends Genet 1990, 6:121-125.

3. Birkedal-Hansen $\mathrm{H}$ : Proteolytic remodeling of extracellular matrix. Curr Opin Cell Biol 1995, 7:728-735.

4. Lo EH, Wang $X$, Cuzner ML: Extracellular proteolysis in brain injury and inflammation: role for plasminogen activators and matrix metalloproteinases. J Neurosci Res 2002, 69:1-9.

5. Irigoyen JP, Munoz-Canoves $P$, Montero L, Koziczak M, Nagamine $Y$ : The plasminogen activator system: biology and regulation. Cell Mol Life SCi 1999, 56:104-132.

6. Akassoglou K, Kombrinck KW, Degen JL, Strickland S: Tissue plasminogen activator-mediated fibrinolysis protects against axonal degeneration and demyelination after sciatic nerve injury. J Cell Biol 2000, 149:1157-1166.

7. Gveric D, Herrera B, Petzold A, Lawrence DA, Cuzner ML: Impaired fibrinolysis in multiple sclerosis: a role for tissue plasminogen activator inhibitors. Brain 2003, 126:1590-1598.

8. Hohlfeld R, Wekerle $\mathrm{H}$ : Autoimmune concepts of multiple sclerosis as a basis for selective immunotherapy: from pipe dreams to (therapeutic) pipelines. Proc Natl Acad Sci U S A 2004, 101(Suppl 2):14599-14606.

9. East $E$, Baker D, Pryce $G$, Lijnen HR, Cuzner ML, Gveric D: A role for the plasminogen activator system in inflammation and neurodegeneration in the central nervous system during experimental allergic encephalomyelitis. Am J Pathol 2005, 167:545-554.

10. Gveric D, Hanemaaijer R, Newcombe J, van Lent NA, Sier CF, Cuzner ML: Plasminogen activators in multiple sclerosis lesions: implications for the inflammatory response and axonal damage. Brain 2001, 124:1978-1988.

11. Washington RA, Becher B, Balabanov R, Antel J, Dore-Duffy P: Expression of the activation marker urokinase plasminogen-activator receptor in cultured human central nervous system microglia. J Neurosci Res 1996 45:392-399.

12. Teesalu T, Hinkkanen AE, Vaheri A: Coordinated induction of extracellular proteolysis systems during experimental autoimmune encephalomyelitis in mice. Am J Pathol 2001, 159:2227-2237.

13. Mondino A, Blasi F: UPA and UPAR in fibrinolysis, immunity and pathology. Trends Immunol 2004, 25:450-455.

14. Krakovsky M, Polianski V, Nimrod A, Higazi A, Leker RR, Lamensdorf I: THR18, a 18-mer peptide derived from PAI-1, is neuroprotective and improves thrombolysis by tPA in rat stroke models. Neurol Res 2011, 33:983-990.

15. Lourbopoulos A, Grigoriadis N, Lagoudaki R, Touloumi O, Polyzoidou E, Mavromatis I, Tascos N, Breuer A, Ovadia H, Karussis D, et al: Administration of 2arachidonoylglycerol ameliorates both acute and chronic experimental autoimmune encephalomyelitis. Brain Res 2011, 1390:126-141.

16. Lourbopoulos Athanasios G, Constantina S, Georgia D, Nikolaos T, Esther S, Nikolaos G: Modified Bielschowsky silver impregnation combined with Hematoxylin or Cresyl Violet counterstaining as a potential tool for the simultaneous study of inflammation and axonal injury in the central nervous system. Aristotle Univ Med J 2007, 34:31-39.

17. Kettenmann H, Hanisch UK, Noda M, Verkhratsky A: Physiology of microglia. Physiol Rev 2011, 91:461-553.

18. Rosenmann H, Grigoriadis N, Karussis D, Boimel M, Touloumi O, Ovadia H, Abramsky O: Tauopathy-like abnormalities and neurologic deficits in mice immunized with neuronal tau protein. Arch Neurol 2006, 63:1459-1467.

19. Benveniste EN: Role of macrophages/microglia in multiple sclerosis and experimental allergic encephalomyelitis. J Mol Med (Berl) 1997, 75:165-173.

20. Carson MJ: Microglia as liaisons between the immune and central nervous systems: functional implications for multiple sclerosis. Glia 2002, 40:218-231.

21. Ambrosini E, Aloisi F: Chemokines and glial cells: a complex network in the central nervous system. Neurochem Res 2004, 29:1017-1038.

22. East E, Gveric D, Baker D, Pryce G, Lijnen HR, Cuzner ML: Chronic relapsing experimental allergic encephalomyelitis (CREAE) in plasminogen activator inhibitor-1 knockout mice: the effect of fibrinolysis during neuroinflammation. Neuropathol Appl Neurobiol 2008, 34:216-230.

23. Smiley ST, King JA, Hancock WW: Fibrinogen stimulates macrophage chemokine secretion through toll-like receptor 4. J Immunol 2001, 167:2887-2894

24. Flick MJ, Du X, Witte DP, Jirouskova M, Soloviev DA, Busuttil SJ, Plow EF, Degen $J$ : Leukocyte engagement of fibrin(ogen) via the integrin 
receptor alphaMbeta2/Mac-1 is critical for host inflammatory response in vivo. J Clin Invest 2004, 113:1596-1606.

25. Adams RA, Passino M, Sachs BD, Nuriel T, Akassoglou K: Fibrin mechanisms and functions in nervous system pathology. Mol Interv 2004, 4:163-176.

26. Cruz-Topete D, Iwaki T, Ploplis VA, Castellino FJ: Delayed inflammatory responses to endotoxin in fibrinogen-deficient mice. J Pathol 2006, 210:325-333.

27. Gyetko MR, Wilkinson CC, Sitrin RG: Monocyte urokinase expression: modulation by interleukins. J Leukoc Biol 1993, 53:598-601.

28. Gyetko MR, Shollenberger SB, Sitrin RG: Urokinase expression in mononuclear phagocytes: cytokine-specific modulation by interferongamma and tumor necrosis factor-alpha. J Leukoc Biol 1992, 51:256-263.

29. Gundersen D, Tran-Thang C, Sordat B, Mourali F, Ruegg C: Plasmin-induced proteolysis of tenascin-C: modulation by $T$ lymphocyte-derived urokinase-type plasminogen activator and effect on T lymphocyte adhesion, activation, and cell clustering. J Immunol 1997, 158:1051-1060.

30. Bianchi E, Ferrero E, Fazioli F, Mangili F, Wang J, Bender JR, Blasi F, Pardi R: Integrin-dependent induction of functional urokinase receptors in primary T lymphocytes. J Clin Invest 1996, 98:1133-1141.

31. Nykjaer A, Moller B, Todd RF 3rd, Christensen T, Andreasen PA, Gliemann J, Petersen CM: Urokinase receptor. An activation antigen in human T lymphocytes. J Immunol 1994, 152:505-516.

32. Cohen SD, Israel E, Spiess-Meier B, Wainberg MA: Plasminogen activator is an apparent lymphocyte mitogen. J Immunol 1981, 126:1415-1420.

33. Gudewicz PW, Gilboa N: Human urokinase-type plasminogen activator stimulates chemotaxis of human neutrophils. Biochem Biophys Res Commun 1987, 147:1176-1181.

34. Gyetko MR, Sud S, Chen GH, Fuller JA, Chensue SW, Toews GB: Urokinasetype plasminogen activator is required for the generation of a type 1 immune response to pulmonary Cryptococcus neoformans infection. J Immunol 2002, 168:801-809.

35. Carmeliet P, Schoonjans L, Kieckens L, Ream B, Degen J, Bronson R, De Vos $\mathrm{R}$, van den Oord JJ, Collen D, Mulligan RC: Physiological consequences of loss of plasminogen activator gene function in mice. Nature 1994, 368:419-424.

36. Bugge TH, Flick MJ, Danton MJ, Daugherty CC, Romer J, Dano K, Carmeliet $P$, Collen D, Degen JL: Urokinase-type plasminogen activator is effective in fibrin clearance in the absence of its receptor or tissue-type plasminogen activator. Proc Natl Acad Sci U S A 1996, 93:5899-5904.

37. Carmeliet P, Stassen JM, Schoonjans L, Ream B, van den Oord JJ, De Mol M, Mulligan RC, Collen D: Plasminogen activator inhibitor-1 gene-deficient mice. II. Effects on hemostasis, thrombosis, and thrombolysis. J Clin Invest 1993, 92:2756-2760.

doi:10.1186/1742-2094-10-124

Cite this article as: Gur-Wahnon et al: The plasminogen activator system: involvement in central nervous system inflammation and a potential site for therapeutic intervention. Journal of Neuroinflammation 2013 10:124.

\section{Submit your next manuscript to BioMed Central and take full advantage of:}

- Convenient online submission

- Thorough peer review

- No space constraints or color figure charges

- Immediate publication on acceptance

- Inclusion in PubMed, CAS, Scopus and Google Scholar

- Research which is freely available for redistribution 